\title{
Fetal leg posture in uncomplicated breech and cephalic pregnancies
}

\author{
Bianca F. Fong • Geert J. P. Savelsbergh • \\ Johanna I. P. de Vries
}

Received: 24 March 2008 / Accepted: 19 May 2008/Published online: 26 July 2008

(C) The Author(s) 2008

\begin{abstract}
Background The objective of our study was to determine differences in prenatal leg posture development between breech and cephalic-born babies. Materials and methods Ten healthy fetuses in breech and ten healthy fetuses in cephalic presentation were observed by means of weekly ultrasounds from 33 weeks gestational age until birth to assess leg posture. Results The breech fetuses showed a clear preference for an extended leg position; they spent significantly more time with their knees in extension than the cephalic fetuses $(p<0.001)$. The cephalic fetuses showed significantly more leg-crossing than the breech fetuses $(p<0.01)$. For both findings, no significant change over time could be observed in either group. Conclusion These findings show that the intra-uterine position does influence the fetal postural and motor development. However, it seems unlikely that intra-uterine movement restriction can solely be held accountable for the observed differences in leg position between breech and cephalic fetuses.
\end{abstract}

Keywords Breech · Leg posture · Pregnancy ·

Fetal movement $\cdot$ Ultrasonography

B. F. Fong · G. J. P. Savelsbergh · J. I. P. de Vries

Research Institute MOVE,

Faculty of Human Movement Sciences, VU University,

Amsterdam, The Netherlands

B. F. Fong $(\varangle) \cdot$ J. I. P. de Vries

Department of Obstetrics and Gynaecology,

VU University Medical Centre,

Amsterdam, The Netherlands

e-mail: b.f.fong@mca.nl

\section{G. J. P. Savelsbergh}

Institute for Biophysical and Clinical Research into Human

Movement, Manchester Metropolitan University,

Manchester, UK

\section{Introduction}

During the last decade, the influence of fetal breech presentation on child development, both in the early neonatal life, as well as in the long term, has been the focus of many studies. Especially, the consequences of the mode of delivery on postnatal development in breech pregnancies remain a hot topic $[5,9,17]$. There is a clear association between breech presentation and prematurity, fetal abnormalities (for example, neuromotor abnormalities), and uterine malformations. Still, for more than $80 \%$ of breech fetuses at term, no explanation can be found for this presentation. Awareness of the prenatal influence of the breech presentation on the motor capacities of the lower extremities, regardless of the mode of delivery, dates back from the late 1950s [10]. Breech presentation is known to be one of the major risk factors for congenital hip dysplasia [4, 13], with an odds ratio of 5.5 being reported [12]. Pioneering work on the relationship between actual prenatal leg postures and neonatal motor outcome in a cohort of infants born in breech has been performed by the group of Sival et al. [16]. They described long-term alterations in the development of motor functions (leg posture, reflexes, and posture while walking) that could be caused by intra-uterine movement restriction of the legs.

Due to the development and the widespread use of ultrasound techniques, our knowledge on intra-uterine behavior in normal and complicated pregnancies has vastly increased. Changes in intra-uterine environment can influence the development of motor, as well as postural aspects of fetal behavior. Concerning the motor activity, limitation of the environment by reduced amniotic fluid was found to result in the temporary reduction of qualitative aspects of fetal and neonatal movement [15]. Environmental influences have been suggested to play a role in the preference 
posture of the fetal head, as well as fetal arm, position in breech fetuses when compared to cephalic fetuses $[6,7]$.

With regard to the fetal legs, factors which might contribute to a different intra-uterine environment when comparing breech to cephalic fetuses are the difference in distribution of amniotic fluid within the lower uterine cavity, and also the shape of the lower segment of the uterus in contrast to the fundus and the surrounding pelvic bones. The aim of this study was to enhance our understanding about prenatal leg posture development and differences between breech and cephalic-born babies. Therefore, we studied the intra-uterine development of leg position in these groups during the last trimester of pregnancy.

\section{Materials and methods}

Two groups of fetuses were studied. Ten healthy women with a fetus in breech presentation at 33 weeks gestational age and 10 healthy women with a fetus in cephalic presentation volunteered and gave their informed consent to participate in this investigation after being informed about the aims and methods of the study. The gestational ages were reliably dated and confirmed by an early ultrasound scan. An extensive ultrasound examination was performed at 20 weeks gestation in order to exclude congenital abnormalities. No therapeutic drugs were allowed. The study was approved by the Medical Ethics Committee of the VU University Medical Centre. Fetal leg position was studied longitudinally with weekly real-time ultrasound observations, starting from 33 weeks gestational age (in two cases, from 34 weeks) until birth in both the breech and the cephalic groups. The ultrasound examinations were performed with an Aloka SSD-1700 Dyna View real-time scanner with a $3.5-\mathrm{MHz}$ transducer. The recordings were made in a quiet room with the women lying in a comfortable semi-recumbent position, slightly tilted to the left. The women were asked not to drink coffee, tea, alcoholic beverages, or smoke for $2 \mathrm{~h}$ prior to the recording. Recordings took place between 08:00 and 18:00 h, in a period of relative fetal quiescence. All images were videotaped for off-line analysis.

\section{Scanning procedure}

Each observation started with the assessment of the fetal presentation (breech or cephalic). The amniotic fluid index (AFI) was measured at each assessment. As part of a research project in which the fetal head, arm, and leg position were studied during 1-h ultrasound sessions, the leg position was observed for $15 \mathrm{~min}$, alternating between left and right leg every $30 \mathrm{~s}$.

\section{Data extraction}

During a video replay session, three different aspects of fetal leg position were assessed every $30 \mathrm{~s}$. First, the angle between the upper and the lower leg (knee angle) was observed to determine if the legs were flexed or extended. If the knee angle was greater than $135^{\circ}$, the leg position was scored as extended. All knee angles $<135^{\circ}$ were considered as flexion.

Second, we looked at the angle between the lower leg and the foot (ankle angle) to determine if the fetal feet were extended (fetal foot in line with the fetal lower leg) or flexed (all other positions of the fetal foot).

Unfortunately, with 2-D ultrasound techniques, assessment of the angle between the fetal hip and torso proved not to be possible. Because of the importance of the position of the hip joint, especially when comparing breech fetuses to cephalic fetuses, we tried to obtain an impression of the amount of abduction in the hip joint. Therefore, we assessed if the lower part of the fetal legs were either crossed over each other or if they lay uncrossed besides each other.

The whole procedure was repeated twice a minute, providing 31 assessments of leg position for each leg during every 15 -min recording. If the fetal leg was moving or if the quality of the image was insufficient at a sampling moment, an interval of $5 \mathrm{~s}$ prior to or after that moment was used to determine the leg position.

All children were neurologically examined in the first week after birth and at one year of age. All breech babies were screened for congenital hip dislocation by ultrasound examination of the hip joints via the regular postnatal care check-ups at three months.

To evaluate inter-observer agreement, the leg position of five randomly selected fetuses at different gestational ages was analyzed by two observers (BF and JdV). Cohen's Kappa was calculated for these observations and reached a value of 0.90 for knee angle, 0.70 for ankle angle, and 0.71 for leg crossing.

\section{Data analysis}

The fetal leg position is presented in percentages of the recording time. To determine if there was a significant difference in extension between the right and the left leg, a Wilcoxon signed rank test was performed for knee angle per studied gestational age and for both groups.

To determine if there was significant change in extension over time, a Friedman two-way analysis of variance was performed for both joints in both groups. For both groups of fetuses, the percentage of the recording time in which they had their legs crossed is presented. A $t$-test was performed to determine if there was a significant difference 
Table 1 Clinical data for the breech and the cephalic groups

\begin{tabular}{lll}
\hline & $\begin{array}{l}\text { Breech }(n=10), \text { median } \\
\text { (range) }\end{array}$ & $\begin{array}{l}\text { Cephalic }(n=10), \\
\text { median (range) }\end{array}$ \\
\hline Maternal age & $35(31-42)$ & $35(27-37)$ \\
Parity: P0/P1 & $6 / 4$ & $10 / 0$ \\
Sex: F/M & $8 / 2$ & $3 / 7$ \\
GA at birth & $38(36-39)$ & $40(37-42)$ \\
$\quad$ (weeks) & & $3,635(3,070-4,400)$ \\
Birth weight & $3,088(2,800-3,730)$ & \\
$\quad$ g) & & $9(5-10)$ \\
1-min AS & $9(6-10)$ & $10(6-10)$ \\
5-min AS & $10(8-10)$ & $7.18(7.09-7.33)$ \\
UapH & $7.27(7.07-7.32)$ & \\
\hline
\end{tabular}

$\mathrm{F}=$ female; $\mathrm{M}=$ male; $\mathrm{P} 0=$ nulliparous; $\mathrm{P} 1=$ primiparous; $\mathrm{GA}=$ gestational age; $\mathrm{AS}=$ Apgar score; $\mathrm{UapH}=$ umbilical arterial $\mathrm{pH}$

between both groups in the percentage of time they spend with their legs crossed.

\section{Results}

For the breech fetuses, the mean percentage of recordings with optimal visualization was $95 \%$ for knee angle and $63 \%$ for ankle angle. Optimal visualization in the cephalic group was $94 \%$ of recordings for knee angle and $86 \%$ for ankle angle. The AFIs were within the normal ranges, with the exception of one breech fetus having AFIs below the 5 th centile at all registrations. This fetus showed no outliers in the results.

Nine babies in the breech group were born by caesarean section (CS) due to various reasons: cephalo-pelvic disproportion, inadequate progression of labor, oligohydramnios, and footling presentation. In the cephalic group, one baby was delivered by CS because of inadequate progression of labor; the others were born vaginally. One vacuum extraction had to be performed in this group because of fetal distress during the second stage of labor. The babies in

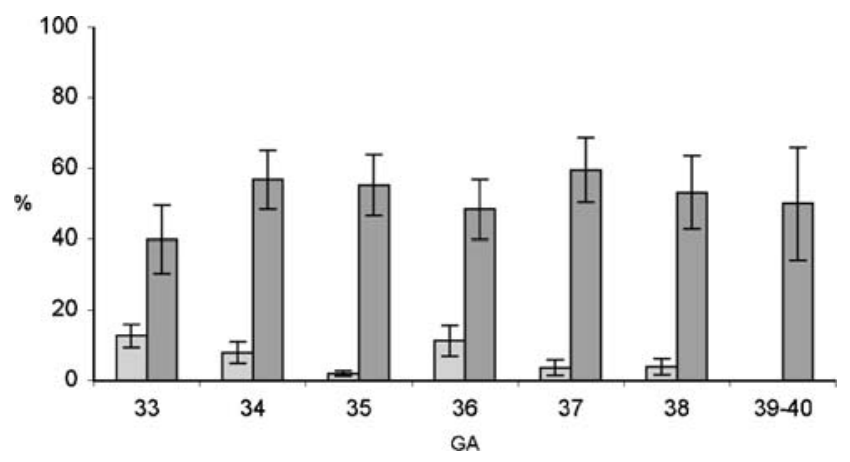

Fig. 1 Light-grey bars=cephalic group; dark-grey bars=breech group; $\%=$ percentage of observation time; $\mathrm{GA}=$ gestational age (in weeks) the breech group were born significantly earlier $(p=0.025)$ than those in the cephalic group (Table 1).

One baby in the breech group was born at 36 weeks; the others between 37 and 39 weeks gestational age. The cephalic group babies were born between 38 and 42 weeks gestational age. The birth weights in the breech group were significantly lower than those in the cephalic group $(p=0.025)$, which may probably be explained by the significant difference in gestational age at birth. All babies in both groups, however, had birth weights $>10$ th centile [11].

There were no significant differences between the breech and the cephalic group concerning 1- and 5-min Apgar scores and umbilical arterial $\mathrm{pH}$. There were more girls among the breech ( 8 out of 10$)$ than among the cephalic babies ( 3 out of 10). Also, 6 out of 10 participants in the breech group were primiparous, whereas all participants in the cephalic group were nulliparous. All children were neurologically examined in the first week after birth and at one year of age, they were all neurologically normal. None of the children in the breech group showed signs of congenital hip dislocation at ultrasound examination of the hips at about 3 months of age.

We found no significant differences between the extension percentages for the right and the left knee in either group. Having determined this, we put together the data for the left and right knee angle by calculating the means from the raw data for each fetus at every studied gestational age. Thus, for every recording, we now have only one knee extension percentage for each fetus. These are the data we used for further analysis.

For both groups, the ankle angle showed almost exclusively a flexed position. Very sporadically could extension of the ankle angle be observed. This holds true for all gestational ages. Therefore, we have chosen not to present the data on ankle angles in a figure.

Extension of the leg in percentage of the recording time is shown for both groups of fetuses in the gestational weeks studied (Fig. 1). The breech fetuses show a clear preference for an extended leg position; they spent significantly more

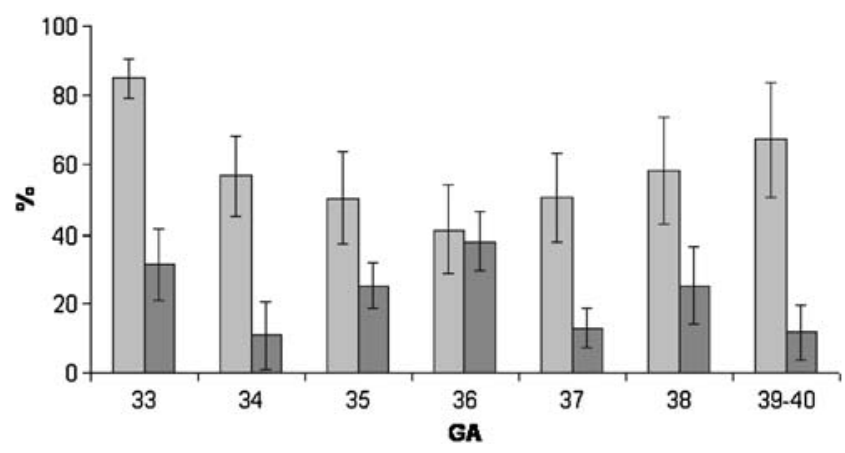

Fig. 2 Light-grey bars=cephalic group; dark-grey bars=breech group; $\%=$ percentage of observation time; $\mathrm{GA}=$ gestational age (in weeks) 
time with their knees in extension than did the cephalic fetuses $(p<0.001)$. No significant change over time could be observed for either group.

Lower legs crossed over one another in percentage of the recording time are depicted for both groups in Fig. 2. The cephalic fetuses showed significantly more leg crossing than the breech fetuses $(p<0.01)$. Again, no significant change in time could be observed in both groups.

\section{Discussion}

As far as we know, we were the first group to longitudinally study leg position in healthy breech and cephalic fetuses. We found considerable differences between both groups. First, the breech fetuses prefer to have their knees in an extended position when compared to the cephalic group. Second, when looking at the position of the lower part of the legs, the cephalic fetuses show a significantly more outspoken preference for crossing one leg over the other. An interesting finding was that, for both groups, there was no significant change in preference leg position with advancing gestational age. No difference was found in the ankle position. In both groups, the ankles were almost exclusively flexed. This is in agreement with observations in preterm infants from 28 weeks onwards [1].

In fetuses in breech presentation, movement restriction of the fetal hips is always thought to play a major role in the development of postnatal leg movement restriction. The greatest impact of movement restriction can be expected towards the end of pregnancy, when the fetal hips are surrounded by the bony maternal pelvis in singleton breech pregnancies. Breech twins do not show a higher prevalence of hip joint instability and congenital hip dysplasia compared with their cephalic-born sibling [14]. This is probably because of the different kind of breech position in twins (with flexed knees and hips, as opposed to the more common frank breech in singletons). Also, non-twins mostly assume their breech position earlier than twins with consequently a longer period of mechanical constraint on the hips. We found that the differences in fetal leg position between breech and cephalic fetuses could already be observed starting from early in the third trimester, when movement restriction is not thought to be significant, and also because, mostly, the breech will not be engaged yet in the maternal pelvis at this time. This makes it unlikely that the duration of differences in movement freedom of the hips can solely be held responsible for these findings. Could there, in fact, be an intrinsic factor which makes breech fetuses assume a leg position with extension in the knees, maybe even causing their abnormal presentation [2]?
A leg position with crossing of one lower leg over the other, as we observed in our cephalic fetuses, could, theoretically, lead to a more abducted hip position in utero than when the legs are uncrossed. As abduction of the hip joint facilitates normal development of the femoral head and the acetabulum [3], the observed preference leg position of our breech fetuses with extended legs and uncrossed lower legs could be one of the reasons why breech fetuses show a significant risk of developing neonatal hip joint instability.

Long-term effects of intra-uterine breech position on locomotion at 2.5 years were studied in the same population [8]. The breech- and cephalic-born infants performed equally well during walking and gap crossing. However, the total amount of extra hip motion during gap crossing was significantly smaller in the breech group. Apparently, they reach the same maximum gap crossing distance differently than the cephalic infants.

Environmental influence was found not to be limited to the legs. In previous publications on observations in the same groups of fetuses, we found that the development of a lateralized head position preference was clearly less outspoken in the breech fetuses when compared to the cephalic fetuses, especially after 36 weeks gestational age [7]. When studying the development of arm posture, we observed that, after 36 weeks gestational age, the breech fetuses showed significantly less wrist flexion when compared to the cephalic fetuses [6].

These findings seem to provide further confirmation that the intra-uterine position does influence the fetal postural and motor development, although, considering our findings, it seems unlikely that intra-uterine movement restriction can solely be held accountable for the observed differences in intra-uterine leg position between breech and cephalic fetuses. Long-term effects were not found in this small population concerning hip dysplasia, nor in locomotion at 2.5 years, since the task of gap crossing during locomotion was performed differently.

Open Access This article is distributed under the terms of the Creative Commons Attribution Noncommercial License which permits any noncommercial use, distribution, and reproduction in any medium, provided the original author(s) and source are credited.

\section{References}

1. Amiel-Tison C (1968) Neurological evaluation of the maturity of newborn infants. Arch Dis Child 43:89-93

2. Bartlett D, Okun N (1994) Breech presentation: a random event or an explainable phenomenon? Dev Med Child Neurol 36:833-838 
3. Bradley J, Wetherill M, Benson MK (1987) Splintage for congenital dislocation of the hip. Is it safe and reliable? J Bone Joint Surg Br 69:257-263

4. Chan A, McCaul KA, Cundy PJ, Haan EA, Byron-Scott R (1997) Perinatal risk factors for developmental dysplasia of the hip. Arch Dis Child Fetal Neonatal Ed 76:F94-F100

5. Danielian PJ, Wang J, Hall MH (1996) Long-term outcome by method of delivery of fetuses in breech presentation at term: population based follow up. BMJ 312:1451-1453

6. Fong BF, Buis AJ, Savelsbergh GJ, de Vries JI (2005) Influence of breech presentation on the development of fetal arm posture. Early Hum Dev 81:519-527 doi:10.1016/j.earlhumdev.2004.11.003

7. Fong BF, Savelsbergh GJ, van Geijn HP, de Vries JI (2005) Does intra-uterine environment influence fetal head-position preference? A comparison between breech and cephalic presentation. Early Hum Dev 81:507-517 doi:10.1016/j.earlhumdev.2007.04.004

8. Fong BF, Ledebt A, Zwart R, de Vries JI, Savelsbergh GJ (2008) Is there an effect of prenatal breech position on locomotion at 2.5 years? Early Hum Dev 84:211-216 doi:10.1016/ j.earlhumdev.2004.11.002

9. Hannah ME, Hannah WJ, Hewson SA, Hodnett ED, Saigal S, Willan AR (2000) Planned caesarean section versus planned vaginal birth for breech presentation at term: a randomised multicentre trial. Term Breech Trial Collaborative Group. Lancet 356:1375-1383 doi:10.1016/S0140-6736(00)02840-3

10. Herlitz G (1959) Limitation of movement of the hip joints in newborn infants following breech presentation. Acta Paediatr Suppl 48:123-125 doi:10.1111/j.1651-2227.1959.tb05417.x
11. Kloosterman GJ (1970) On intrauterine growth: the significance of prenatal care. Int J Gynecol Obstet 8:895-912

12. Lehmann HP, Hinton R, Morello P, Santoli J (2000) Developmental dysplasia of the hip practice guideline: technical report. Committee on Quality Improvement, and Subcommittee on Developmental Dysplasia of the Hip. Pediatrics 105:E57 doi:10.1542/peds.105.4.e57

13. Luterkort M, Persson PH, Polberger S, Bjerre I (1986) Hip joint instability in breech pregnancy. Acta Paediatr Scand 75:860-863 doi:10.1111/j.1651-2227.1986.tb10303.x

14. Rühmann O, Lazović D, Bouklas P, Rössig S (1998) Ultrasound hip joint screening in newborn infants. Is twin pregnancy a risk factor for dysplasia? Ultraschall Med 19:64-69

15. Sival DA, Visser GH, Prechtl HF (1990) Does reduction of amniotic fluid affect fetal movements? Early Hum Dev 23:233246 doi:10.1016/0378-3782(93)90009-J

16. Sival DA, Prechtl HF, Sonder GH, Touwen BC (1993) The effect of intra-uterine breech position on postnatal motor functions of the lower limbs. Early Hum Dev 32:161-176 doi:10.1016/0378-3782 (90)90014-A

17. Whyte H, Hannah ME, Saigal S, Hannah WJ, Hewson S, Amankwah K, Cheng M, Gafni A, Guselle P, Helewa M, Hodnett ED, Hutton E, Kung R, McKay D, Ross S, Willan A; Term Breech Trial Collaborative Group (2004) Outcomes of children at 2 years after planned cesarean birth versus planned vaginal birth for breech presentation at term: the International Randomized Term Breech Trial. Am J Obstet Gynecol 191:864-871 doi:10.1016/j.ajog.2004.06.056 